\title{
Panorama da produção literária de Milton Hatoum e de sua recepção, em homenagem aos vinte anos de Relato de um certo Oriente
}

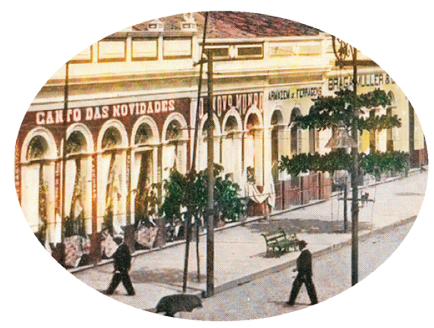

Joanna da Silva*

\section{Resumo}

Com vistas a homenagear o vigésimo aniversário de Relato de um certo Oriente, primeiro trabalho de Milton Hatoum, este artigo consiste em uma visão panorâmica da produção literária do escritor amazonense desde sua obra de estréia até o momento presente. Tomando-se como perspectiva a Estética da Recepção, uma ênfase maior é dada à sua primeira obra, bem como às diferentes leituras e interpretações deste trabalho pela crítica literária contemporânea.

Palavras-chave: Milton Hatoum; produção literária; estética da recepção.

\begin{abstract}
With a view to pay a homage to Milton Hatoum's first work, Relato de um certo Oriente, for its twentieth anniversary, this paper consists on na overview of Hatoum's literary production since his première until the present day. Taking the Critical Reception as a perspective of analysis, a major emphasis is given to his first work, as well as to the different readings and interpretations of this work by contemporary literary critic.
\end{abstract}

Keywords: Milton Hatoum; literary production; critical reception.

\footnotetext{
* Mestranda em Teoria Literária e Crítica da Cultura/UFSI-MG - Prof. UFAM/IEAA. E-mail: jo-humaita@ufam. edu.br - Instituição de fomento: Fapeam.
} 


\section{Introdução}

A obra Relato de um certo Oriente, publicada em 1989, ${ }^{2}$ foi o primeiro livro lançado por Milton Hatoum, escritor amazonense que tem recebido um extraordinário reconhecimento da crítica brasileira e estrangeira como um grande talento da atualidade, e que, até este ano de 2009, já produziu cinco livros, sendo o último uma coletânea de contos intitulada Cidade ilhada (2009).

Filho de pai árabe e mãe amazonense de origem libanesa, Hatoum nasceu em Manaus em 1952, onde estudou em escola pública, em contato com diferentes classes e etnias - caboclos, índios, negros, filhos de desembargadores, comerciantes, lavadeiras, porteiros e operários. Tal vivência consistiu em uma experiência fundamental para sua formação, na medida em que lhe permitiu uma visão de mundo que transcendesse os limites da classe média/alta à qual pertencia e que era considerada a elite manauense àquela época.

Hatoum formou-se em Arquitetura e Urbanismo pela USP em 1970, onde também recebeu o título de mestre em Letras. Na década de 1980 mudou-se para a França, onde cursou pós-graduação na Universidade de Paris. Foi professor de Língua e Literatura Francesa na Universidade Federal do Amazonas de 1984 a 1988. Titulou-se doutor em Teoria Literária na USP em 1998 e atualmente atua como professor visitante na Universidade da Califórnia, em Berkeley.

Suas narrativas, que geralmente focalizam uma época específica, a década de 1950, têm como cenário a região amazônica - sobretudo a cidade de Manaus. Esse detalhe é relevante para o entendimento das obras de Hatoum na medida em que, conforme observa Chiarelli (2005), a leitura de seus romances suscita dois aspectos que se impõem na relação entre o regional e o regionalismo. O primeiro refere-se ao fato de seus romances focalizarem o Amazonas, sem, no entanto, serem regionalistas, pois evitam sublinhar apenas os aspectos exóticos dessa região; e o segundo diz respeito ao fato de Hatoum ser brasileiro e, enquanto tal, refugar a representação de aspectos exóticos do País. Em entrevista recente, o próprio autor fez a seguinte afirmação:

Não sou filho da floresta, a floresta não é meu habitat. A minha literatura é urbana, mas com muitos vínculos com a floresta, o rio. Acho que o lugar da literatura é o lugar da infância. Aonde vou, levo Manaus comigo. Mas não uma 
Manaus qualquer. É a Manaus do começo dos anos 1960, fim dos anos 1950 (HATOUM apud GURGEL, 2008, p. 3).

Nessa perspectiva, este artigo, que consiste em uma homenagem a publicação de Relato de um certo Oriente, empreende uma visão panorâmica da produção literária do escritor amazonense desde sua obra de estreia até a atualidade, com ênfase para o romance supracitado. Além disso, ao considerarmos a Estética da Recepção como uma abordagem relevante para se analisar a obra de um autor que possui uma vasta e diversificada fortuna crítica, destacamos as diferentes leituras e interpretações da obra hatouniana pela crítica literária contemporânea.

\section{Panorama das obras de Milton Hatoum}

\subsection{Relato de um certo Oriente}

Relato de um certo Oriente, que conquistou um prêmio Jabuti de melhor romance, já foi publicado em Portugal e traduzido para diversos países, entre eles, Estados Unidos, Itália, Inglaterra, Espanha, Alemanha, Holanda, Líbano e Grécia. A reedição da obra no Brasil, em 2008, chegou a causar certa admiração no próprio autor, que considera "quase um milagre" a obra continuar a ser lida quase duas décadas depois de seu lançamento (LOPES, 2008).

O romance, que remonta à década de 1950, tem como figura central do enredo a presença extraordinária da matriarca Emilie, que constitui um paradigma de mãe amorosa e protetora, que procura conduzir os destinos dos que a cercam. Guardiã dos segredos e mistérios da família, é ela quem traz aninhado ao colo o novelo de histórias familiares e representa, portanto, a origem e o fim do enredo, pois este se concentra nas lembranças que evocarão seu nome e sua trajetória.

Trata-se de uma narrativa memorialística na qual a lembrança é o fio condutor de um emaranhado de imagens, fatos e conflitos que vão se desenrolando diante do leitor, e que são conduzidos pela voz de uma narradora inominada, que regressa, após longos anos de ausência, à casa de sua infância na tentativa de reconstruir, por meio das lembranças e vãos do esquecimento, um mundo perdido e uma casa desfeita. E é justamente por meio de suas 
lembranças e vãos do esquecimento que ela, estabelecendo um diálogo epistolar com o irmão distante, busca recuperar pela mediação da memória a saga de sua família. Com sua força e sua perseverança, essa personagem traz à tona imagens que reconstruíssem seu passado, mas sem a pretensão de uma totalidade, e sim, consciente da possibilidade de se narrar uma fatia de vida, com toda a incompletude que isso encerra.

Assim, essa pessoa de passado incerto, que tem no irmão o destinatário de suas reflexões, retorna à cidade natal em busca de um reencontro com Emilie, sua mãe adotiva. Ao chegar, encontra a casa desfeita, o que transforma seu relato numa busca de um mundo perdido que se reconstruirá nas falas alternadas das personagens que se juntam nessa busca por um passado distante:

É através da voz insegura e lacunar da narradora que são pinçados os fios das reminiscências daqui e d'além mar, dos vários personagens em tempos diversos. $\mathrm{O}$ procedimento de composição do texto não dá hegemonia a qualquer voz, fazendo conviver, no espaço narrativo, memórias de narradores com suas vozes próprias, muitas vezes em desarmonia (CURY, 2000, p. 169).

E tal reconstrução tem como cenário uma cidade ilhada pelo rio e pela floresta amazônica, um porto de recordações num espaço aberto à atmosfera ambígua de um certo oriente, dentro de um espaço flutuante onde velhas tradições religiosas e culturais se (com) fundem.

A tessitura narrativa traz à tona o drama de diferentes personagens, como Samaria Delia e sua a filha Soraya Ângela, cujas histórias são marcadas por momentos de repulsa. A segunda, rejeitada por parte da família por ser surda-muda e filha de pai desconhecido, tem um final trágico na história (morre atropelada na frente da casa da avó), figurando, para a narradora, como "uma das lembranças mais dolorosas da minha infância" (HATOUM, 2002, p. 22) . $^{3}$ Trágico também foi o destino de Amir, irmão de Emilie e tio da narradora, que, vestido de branco, transita para a morte acariciando uma orquídea rara, antes de ser tragado pelas águas escuras do rio Negro.

Ao longo do romance, a narradora vai incorporando em seu relato outros diferentes personagens, entre os quais a empregada Anastácia Socorro, em seu labor diário; o médico Hector Dorado e suas descobertas medicinais 
repassadas pelo curandeiro Lobato Naturidade (Tucumã); o tio Hakim, filho predileto de Emilie e conhecedor de seus segredos mais íntimos guardados no velho baú; Hindié Conceição, amiga de longa data e confidente de Emilie; seu pai, que não se afeiçoava aos costumes locais e seguia sua religião de origem, o Alcorão, e cujas histórias que contava como sendo de sua vida eram mescladas com aquelas das Mil e uma noites.

É frequente, no transcorrer do romance, o afloramento do hibridismo e/ou do heterogêneo, presentes tanto nos costumes quanto na linguagem de seus personagens, como se observa no relato de Hakim acerca de sua vivência nesse ambiente multicultural: "Desde pequeno convivi com um idioma na escola e nas ruas da cidade, e com um outro na Parisiense. E às vezes tinha a impressão de viver vidas distintas" (RO, p. 52).

Cabe justamente à linguagem, segundo Toledo (2007), promover uma mistura das tradições culturais, simbólicas, raciais, religiosas, familiares, culinárias e medicinais dentro da narrativa. Haja vista esta passagem acerca das plantas ornamentais da região, que, para Emilie, possuíam o atributo de "protetoras", devido a seus poderes místicos e medicinais:

Emilie maravilhava-se com a descrição da trepadeira que espantava a inveja, das folhas malhadas de um tajá que reproduz a fortuna de um homem, das receitas de curandeiros que veem em certas ervas da floresta o enigma das doenças mais temíveis, com as infusões de coloração sanguínea aconselhadas para aliviar trinta e seis dores do corpo humano (RO, p. 91).

Outros aspectos podem ser evidenciados em relação aos costumes e tradições que aparecem expostos no decorrer da obra, e que são refletidos na fala e na educação dos filhos, bem como na mistura de valores distintos, expressos na própria decoração do ambiente familiar, como no contraste provocado pelo pedaço de cedro do Líbano pendurado, na parede da sala, ao lado de um remo sagrado que contava a história de uma tribo indígena. Também as festas noturnas, realizadas para receber os patrícios e vizinhos, evidenciam esse hibridismo, na medida em que não raro são regadas a uma mistura de pratos orientais e amazônicos: 
Emilie ajudava Anastácia Socorro a trazer os pães de massa folheada, dobrados como se fossem lenços de seda, e uma cesta com figos da Índia, genipapos, biribas, abacaxis e melancias; e numa cumbuca de barro cozido, entre papoulas colhidas no jardim, havia cachos de pitomba (...) No centro do um pátio iluminado pelo sol equatorial, homens e mulheres repetiam o hábito gastronômico milenar de comer com as mãos o fígado cru de carneiro (RO, p. 58).

Essa multiculturalidade é também expressa no afloramento de sensações sinestésicas, como no trecho em que o aroma das frutas locais desperta em Emilie recordações de sua infância:

O aroma das frutas do "sul" vaporava, se colocadas ao lado do cupuaçu e da graviola, frutas que, segundo Emilie, exalavam um odor durante o dia, e um outro, mais intenso, mais doce, durante a noite. "São frutas para saciar o olfato não a fome", profere Emilie. "Só os figos da minha infância me deixavam estonteada desse jeito. $\mathrm{O}$ aroma dos figos era a ponta de um novelo de histórias narrados por minha mãe" (RO, 2002, p. 89).

De fato, conforme já expresso anteriormente, Emilie é a figura emblemática de toda a narrativa, configurando-se como origem e fim do enredo do romance, como podemos observar ao final da história, quando a narradora relembra com saudade a imagem marcante e soberana da mãe, que tanto significou para ela e para os outros:

Emilie se foi para sempre, comecei a imaginar com os olhos da memória as passagens da infância, as cantigas, os convívios, a fala dos outros, a nossa gargalhada ao escutar o idioma híbrido que Emilie inventava todos os dias (...) Era como se eu tentasse sussurrar no teu ouvido a melodia de uma canção sequestrada, e que, pouco a pouco, notas esparsas e frases sincopadas moldavam e modulavam a melodia perdida (RO, p. 166). 


\subsection{Demais obras publicadas por Hatoum}

No ano 2000, Hatoum lança seu segundo romance, Dois Irmãos, um drama familiar em cujo centro estão dois filhos de imigrantes libaneses, os gêmeos Yakub e Omar, e suas relações com a família. Nesta obra, os conflitos transcendem o limite geográfico da casa e estendem-se à cidade e ao rio, de modo que Manaus e o rio Negro transformam-se em símbolos das ruínas e da passagem do tempo.

Dois Irmãos tem por narrador o personagem Nael, filho de Domingas, uma empregada de origem indígena. Recolhido em seu canto, Nael, enquanto focalizador, observa personagens que se entregam ao desejo incestuoso e à vingança. A exemplo da narradora de Relato de um certo Oriente, Nael traz em seu âmago incontáveis amarguras e frustrações. Outros pontos de convergência entre os dois são o conflito identitário, a posição social e familiar e a reconstrução de uma história para a família pela mediação de ruínas e fragmentos da memória. Ademais, ambos se encontram, paradoxalmente, dentro e fora de um círculo familiar, na medida em que veem as personagens por um ângulo diferente - no fundo, são narradores à margem de suas famílias.

Em 2005 Hatoum lança sua terceira obra, Cinz̧as do Norte, que o consagra definitivamente como escritor, conferindo-lhe cinco prêmios no ano seguinte: Prêmio Jabuti de melhor livro e melhor romance (assim qual os dois anteriores), Prêmio Portugal Telecom, o grande prêmio da APCA e o prêmio Bravo.

Cumpre destacar que, longe de indicar uma direção precisa, o "norte" do título remete a um projeto pessoal interrompido. Trata-se de uma metáfora válida tanto para os personagens que acabam em cinzas quanto para a cidade destruída e reconstruída várias vezes, como são as cidades latino-americanas vitimadas pelo "processo civilizatório" europeu. Esse norte, portanto, constitui o direcionamento de uma trajetória de vida que termina em cinzas, sendo tragada pelas adversidades, pelos desencontros, culminando com um destino que também se converte em cinzas.

Já em março de 2008, o escritor publica Órfãos do Eldorado, novela ambientada no final do ciclo seringueiro na Amazônia, e que consiste no relato de sonho e pesadelo. Essa narrativa, que faz um mergulho no passado, nos conflitos familiares e num certo desencanto em relação ao País, é conduzida pelo personagem Arminto, um homem tido como louco em sua solidão e 
velhice e, que relata seu passado de riqueza, desagregação familiar e amores mal resolvidos.

A obra dá continuidade, evidentemente, à temática que o autor havia explorado nos outros três livros, pois constitui um congraçamento entre o mergulho no passado (Relato de um certo Oriente), os conflitos familiares (Dois Irmãos) e o desencanto com o País (Cinzas do Norte), além da profunda ligação com a tradição oral que permeia essas três obras.

Em 2009, Milton Hatoum traz a público sua quinta produção literária, uma coletânea de contos intitulada $A$ cidade ilhada. Seu primeiro livro de contos aborda o enlace de tramas em planos diferentes, nos quais podemos perceber uma inclinação tanto para a crônica quanto para a crítica literária (PINTO, 2009). Trata-se de uma obra que lida com os labirintos da memória a cada conto, pois sua cidade literária/ilhada comunica-se constantemente com outras e, principalmente, com o leitor.

De modo geral, nos romances de Hatoum a memória atua como fio condutor de uma persistente busca pelo passado familiar, uma espécie de tábua de salvação do narrador-náufrago, pois suas narrativas tradicionalmente não trazem uma "solução", uma vez que nenhum dos personagens se salva no final - exceto os narradores, já que sem eles não haveria narrativa. Conforme o próprio Hatoum, "[a] família é tratada como um ritual autofágico, no qual todos se devoram para no fim sobrar apenas a palavra escrita, a memória inventada da tribo" (HATOUM apud BORGES, 2006, s/p).

Em relação aos aspectos estruturais, o escritor tenta construir um universo ficcional fechado e coeso, no qual o fim do romance consiste em uma morte simbólica, uma vez que os narradores, enquanto testemunhas sobreviventes, esgotam toda a sua experiência sobre conflitos e experiências familiares. Há, portanto, uma analogia entre os narradores de Hatoum e a emblemática Sherazade que tece narrativas para não ser decapitada (BORGES, 2006). Essa referência à personagem da literatura oriental se deve também ao fato de a mulher árabe ser (aparentemente) destituída de poder e, ao mesmo tempo, dotada de um grande poder simbólico na qualidade de detentora dos segredos e tradições familiares, como podemos observar nitidamente em Relato de um certo Oriente e Dois Irmãos. É através da reconstrução desse mundo, por meio da memória, que personagens e representações se edificam e se reconstituem 
como representativos de uma cultura e de uma vivência conflituosa, resultante do convívio com a alteridade, com o Outro.

\section{A fortuna crítica}

Conforme afirmado anteriormente, Milton Hatoum se surpreende em ver sua primeira obra, após 20 anos de publicação, ser ainda apreciada pelo público e pela crítica contemporânea. O fato de Hatoum ser um dos escritores brasileiros contemporâneos mais premiados e alvo de recepção crítica numerosa e diversificada torna pertinente que a análise de sua obra leve em consideração os preceitos da Estética da Recepção, corrente crítica surgida na década de 1960 e que possui como marca o reconhecimento da existência do leitor dentro dos estudos literários, juntamente com o autor e o texto (COMPAGNON, 2003).

Essa corrente, que parte do pressuposto que há uma relação da obra com o leitor em um processo comunicativo, considera, na análise de uma obra, sua acolhida alcançada à época de seu aparecimento e sua capacidade de manter-se em diálogo com o público (CONNOR, 1994). Sob essa perspectiva, realizamos um panorama geral da recepção crítica acerca de Relato de um certo Oriente, observando as diferentes possibilidade de leitura de tal romance. Destacamos, inclusive, a posição do próprio escritor acerca de sua própria obra e de seu fazer literário.

Alguns críticos têm-se debruçado sobre os romances de Milton Hatoum sob um enfoque comparatista, observando influências explícitas e implícitas entre Hatoum e outros escritores. Podemos citar, a título de exemplo, Sarah Wells (2007), em seu trabalho intitulado O improvável sucessor de Nassar: a genealogia alternativa de Milton Hatoum; e Marli Fantini (2007), que traça um paralelo entre as obras de Hatoum e Guimarães Rosa no texto Rosa e Hatoum: matizes, mesclas e outras misturas.

Já Stefania Chiarelli (2007), por sua vez, dedicou ao escritor o ensaio, originado de sua tese de doutorado, intitulado Vidas em trânsito - As ficções de Samuel Rawet e Milton Hatoum. Neste texto, a crítica discute temas entre eles a identidade, memória, o imigrante e sua forma de narrar o oriente. Seu ensaio mereceu, inclusive, uma nota do próprio Hatoum: 
É uma rara felicidade ler um ensaio tão bem escrito e estruturado, que analisa com calma e sabedoria vários ângulos dos textos estudados. O livro vai além dos limites de seu objeto, pois constrói um diálogo das obras com uma tradição cultural. O item «memória e narração» me tocou profundamente. E todo o esforço de uma investigação arqueológica (vida e obra) é notável. ${ }^{4}$

O aspecto memorialístico é também muito explorado na recepção pela crítica de Relato de um certo Oriente, uma vez que, conforme já discutido anteriormente, tal aspecto constitui o eixo central da obra, inclusive para o próprio autor, que reforça essa ideia ao declarar que a memória é o chão da sua literatura:

\begin{abstract}
Não há literatura sem memória. A pátria de todo escritor é a infância. Acho que o momento da infância e da juventude é privilegiado para quem quer escrever. É onde a memória sedimenta coisas importantes: as grandes felicidades, os traumas, as alegrias e também as decepções. Certamente não estou falando da lembrança pontual e nítida. O que interessa é a memória desfalcada, a memória não lembrada. Isso é bom para a literatura porque aí é que se instala o espaço da invenção (HATOUM apud GURGEL, 2008, p. 4).
\end{abstract}

Dentre os vários estudiosos que observam o papel da memória como fio condutor nas obras de Hatoum, marcadas pela tentativa de resgate do passado e da história familiar, podemos citar Bridget Christine Arce (2007), em seu artigo Tempo, sentidos e paisagens: os trabalhos da memória em romances de Milton Hatoum, ${ }^{5}$ bem como alguns artigos de Maria Zilda Cury: De orientes e relatos (2000) e Fronteiras da memória na fição de Milton Hatoum (2003).

Para Maria da Luz Pinheiro de Cristo (2007), não há como negar a relevância da questão memorialística presente nas obras de Hatoum:

Em maior ou menos escala, os textos passam pela questão da memória. As discussões contemplam vários modos de aproximação como as ruínas, as imagens, os sentidos, os objetos, os lugares, o esquecimento, sua construção 
ou reconstrução. Consequentemente, focam-se a perda, a destruição e o desaparecimento. Nesse processo de entendimento do funcionamento da memória nos dois romances, é necessário ter em conta o papel da morte. (CRISTO, 2007, p. 10)

Francisco Foot Hardman (2000) também sublinha o papel da memória nas obras do escritor amazonense, chegando até mesmo a contestar o enquadramento de tais obras na rubrica da literatura de imigrantes e/ou na linhagem do regionalismo amazônico. Segundo ele, a literatura hatouniana

(...) interessa aos estudos culturais e literários sobretudo nos entrecruzamentos que traçam entre memória, ficção e história, esta última desdobrada em múltiplas histórias que se traçam, se desenvolvem e se apagam nos planos pessoal, familiar, regional, nacional e internacional. (HARDMAN, 2000, p. 5)

A imigração constitui uma outra vertente é muito explorada pelos críticos desta obra, como se pode verificar em trabalhos como Os novos filhos da dor: Oriente e origem em Milton Hatoum, de Maria A. Ribeiro (2007); e Das águas da memória aos romances de Milton Hatoum: evocação e transferência de culturas, de Jerusa P. Ferreira (2007).

Maria Zilda Cury também afirma, no ensaio Imigrantes na Literatura (2001), ser recorrente na literatura brasileira contemporânea a temática do imigrante e de suas memórias, e que este é símbolo emblemático de identidades em constituição. Em sua opinião, os personagens libaneses das obras de Hatoum - assim também Madruga, personagem da República dos sonhos, de Nélida Pinon, os judeus dos Contos do Imigrante, de Samuel Rawet, e a bailarina sensual de Amrik, de Ana Miranda - ajudam a compor a identidade flutuante do imigrante.

Ainda segundo Cury, agora no artigo De orientes e relatos (2000), o mundo contemporâneo assiste a migrações massivas que constantemente redesenham o perfil de suas populações, fazendo com que a figura do imigrante represente uma "chave conceitual" de grande importância para a compreensão de nosso mundo contemporâneo, pois a presença desse estrangeiro em nosso habitat nos faz perceber a "estrangeiridade" que se faz presente em nosso meio. 
Segundo a crítica,

[...] assim se põe em xeque as identidades que nos foram "outorgadas", exóticas, estereotipadas, que são parte, constitutivamente, da visão que fazemos de nós mesmos. Tal contexto assiste ao nascimento de "uma narrativa híbrida" que converte o passado nacional "naturalizado" como um tempo e espaço monumentalmente estruturados para todo o sempre, em um presente histórico deslocável e aberto a novas enunciações (CURY, 2000, p. 168).

Para Stefania Chiarelli (2007), as linguagens e saberes presentes na literatura do imigrante tornam-se um rico território a ser explorado, pois a alusão à situação de estrangeiridade constitui um ponto de partida para os estudos que buscam investigar como se dá poeticamente a experiência de fronteira entre diferentes culturas. Para essa crítica, a presença de Milton Hatoum, com sua "exuberância narrativa", torna-se imprescindível para os que "desejam vislumbrar a representação da alteridade na literatura" (CHIARELLI, 2007, p. 15). Segundo a autora, em se tratando de multiculturalismo, as obras de Hatoum incentivam uma reflexão acerca da diferença.

Outros conceitos, como o de regionalismo e o exotismo, também são focos de estudos, como nos textos Milton Hatoum e o regionalismo revisitado, de Tânia Pellegrini (2004), e Milton Hatoum e a representação do exótico e do imigrante, deEstela J. Vieira (2007).

Já no horizonte da escrita, para Wander Melo Miranda (2007), Hatoum não cede à facilidade de um exotismo que poderia ser duplamente equivocado. O escritor, segundo Miranda, não reduz à simplicidade a questão entre culturas: "[...] ao contrário, estrangeiros, imigrantes e manauenses compartilham de um território enigmático na sua força sempre estranha e familiar" (MIRANDA, 2007, p. 310).

Essa heterogeneidade cultural se faz presente nas vozes diversas e estranhas que, em Relato de um certo Oriente, impõem à narradora uma dificuldade em relatar os acontecimentos e lembranças ao irmão distante, devido a sua dificuldade em traduzir as diferentes falas e sotaques:

Como traduzir as falas engroladas de uns e os sotaques de outros? Tantas confidências de várias pessoas em tão 
poucos dias ressoavam como um coral de vozes dispersas. Restava então recorrer à minha própria voz, que planaria como um pássaro gigantesco e frágil sobre as outras vozes. (RO, p. 165).

Ao tratar da linguagem utilizada por Hatoum em suas obras, Beth Brait (2008) argumenta que é possível observar um trabalho singular com a língua, que representa uma "dimensão que conduz a um de seus traços característicos: relatos cerzidos com os fios de reminiscências colhidas na rica experiência individual e coletiva, no fértil imaginário que as alimenta"(BRAIT, 2008, p. 34).

Brait também observa que o autor estabelece, por meio do português, sua língua materna, um diálogo com outras línguas, como o árabe, dentro da narrativa, num trabalho singular com a língua, pois, para ela,

[...] a língua com a qual nos expressamos, herdada do ambiente familiar, social, cultural, é muito mais que um instrumento de comunicação. Ela nos constitui, atravessa, faz parte daquilo que, sendo singular em cada indivíduo, tem sua fonte no coletivo e para ele reverte num movimento constante e vital. É sob essa perspectiva que ela se torna uma das matérias-primas de um escritor (BRAIT, 2008, p. 34).

Sabrina Sedlmayer (2005) também aborda o papel da linguagem nas obras hatounianas em seu artigo Perambulações: presença árabe na literatura brasileira. A seu ver, o escritor consegue problematizar não apenas uma certa visão generalista e homogênea do que se convencionou denominar de "literatura de imigrante". Isso porque Hatoum, ao situar sua ficção em Manaus, talvez um dos lugares mais emblemáticos para se falar de uma literatura brasileira imbicada de ressonâncias árabes, consegue deslocar o lugar árabe e implantá-lo no imaginário nacional, num lugar onde, segundo ela, nem“os rios Amazonas e Negro durante um longo curso não se misturam” (SEDLMAYER, 2005, p. 11). Portanto, mediante esse jogo de identidade e diferença, a obra desse escritor apresenta questões relevantes para os estudos literários e culturais (Op. Cit).

Corroborando a importância do papel da linguagem nas obras de Hatoum, Marleide F. de Toledo (2007) observa que o escritor revela uma sensível habilidade em explorar, por meio da linguagem, o que existe de mais 
rico e profundo no ser humano; e ao trazer de volta, por meio de recordações, o pretérito da infância, através de depoimentos, sabores, odores, cores, perfumes e cheiros amazônicos, ele consegue envolver o leitor numa paradoxal melancolia, com explosões de alegria, desilusões e frustrações.

\section{Considerações finais}

A análise de Relato de um certo Oriente permitiu observamos manifestações da memória que delineiam aspectos da tradições de povos de diferentes procedências que dividem um mesmo espaço e que, através de sua fala e de seus atos, manifestam os rastros de uma mistura de tradições e culturas advindas lugares tão distantes e distintos.

Também foi possível perceber, através do resgate feito pela narradora em comunhão com outras vozes que se juntaram a sua, a reconstrução memorialística da família imigrante libanesa, com sua áurea de pompa, mistérios e tradições. Além disso, a cidade de Manaus, o rio e a floresta, com toda sua exuberância, transcendem o mero papel de pano de fundo deste cenário para se transformarem em um campo fértil para a instauração memorialística na qual a mistura e a negação, o confronto e o encontro são as ferramentas para uma negociação cultural que perpassa toda a obra.

Nesse estudo, que também teve como objetivo constatar as abordagens e temáticas já suscitadas e discutidas nas diversas análises da produção literária hatouniana - sobretudo Relato de um certo Oriente, que completa seu vigésimo aniversário em 2009 - foi possível constatar uma recepção crítica bastante favorável à obra de Hatoum, o que ratifica, juntamente com os prêmios recebidos e a aceitação do público, sua qualidade literária. Ademais, mediante os diversos pontos de vista e lugares de enunciação dos críticos que se debruçam sobre a obra de Hatoum, observamos relevantes ângulos para se pensar Relato de um certo Oriente, quer no âmbito dos Estudos Culturais, quer na perspectiva da Crítica Literária tradicional.

Por fim, as considerações feitas por Milton Hatoum a respeito de sua obra e de seu fazer literário também são relevantes, na medida em que permitem estabelecer uma relação entre o autor, a obra e o leitor, conforme a perspectiva da Estética da recepção adotada neste trabalho. 


\section{Notas}

${ }^{1}$ Nesta pesquisa será citada a 2. ed., publicada em 2002.

${ }^{2}$ Doravante a obra será referenciada pela sigla $R O$, seguida do número da página.

${ }^{3}$ Comentário feito por Milton Hatoum na contracapa do livro Vidas em trânsito: As ficções de Samuel Rawel e Milton Hatoum. CHIARELLI, 2007.

${ }^{4}$ Este artigo foi publicado, primeiramente, nos Estados Unidos, pela Luso-brasilian Review, v. 41-1, 2004, p. 121-138.

\section{Referências}

\section{Obras de Milton Hatoum}

HATOUM, Milton. Relato de um certo Oriente. 2. ed. São Paulo: Companhia das Letras, 2002.

HATOUM, Milton. Dois Irmãos. São Paulo: Companhia das Letras, 2000.

HATOUM, Milton. Cinzas do Norte. São Paulo: Companhia das Letras, 2005. HATOUM, Milton. Orfãos do Eldorado. São Paulo: Companhia das Letras, 2008. HATOUM, Milton. Cidade Ilhada. São Paulo: Companhia das Letras, 2009.

\section{Fortuna crítica sobre Hatoum e sua obra}

ARCE, Bridget Christine. Tempo, sentidos e paisagens: Os trabalhos da memória em romances de Milton Hatoum. In: Arquitetura da Memória: ensaios sobre os romances Dois Irmãos, Relato de um certo Oriente e Cinzas do Norte de Milton Hatoum. Manaus: Editora da Universidade Federal do Amazonas/ Uninorte, 2007, p. 219-237.

BRAIT, Beth. A linguagem da memória. Revista Lingua Portuguesa, n. 31. São Paulo: Editora Segmento, 2008, p. 34-35.

CHIARELLI, Stefania. Vidas em trânsito: As ficções de Samuel Rawel e Milton 
Hatoum. São Paulo: Annablue, 2007.

CHIARELLI, Stefania. Retalhos de Brasil. Escrita, n. 6, 2005. Disponível em $<$ http//www.maxwell.lambda.ele.puc-rio.br> Acesso em 10/03/2008.

CURY, Maria Zilda Ferreira. De orientes e relatos. In: SANTOS, Luis Alberto Brandão; PEREIRA, Maria Antonieta (Orgs.) Trocas Culturais. Belo Horizonte: Pós-Lit UFMG, 2000, p. 165-177.

CURY, Maria Zilda Ferreira. Fronteiras da memória na ficção de Milton Hatoum. Letras. Santa Maria, v. 26, 2003, p. 11-19.

CURY, Maria Zilda Ferreira. Imigrantes na Literatura. Vertentes, n. 17, 2001, p. 46-48.

HARDMAN, Francisco Foot. Morrer em Manaus: os avatares da memória em Milton Hatoum. Revista Tempo Brasileiro, n. 14, 2000, p. 5-15.

KRÜGER, Marcos Frederico. O Mito de Origem em Dois Irmãos. Intertextos, v. 3, 2002, p. 203-214.

MIRANDA, Wander Melo. Dois destinos. In: Arquitetura da Memória: ensaios sobre os romances Dois Irmãos, Relato de um certo Oriente e Cinzas do Norte de Milton Hatoum. Manaus: Editora da Universidade Federal do Amazonas/ Uninorte, 2007, p. 310-313.

PELLEGRINI, Tânia. Milton Hatoum e o regionalismo revisitado. Lusobrasilian Review, v. 41-1, 2004, p. 121-138.

PERRONE-MOISÉS, Leyla. A cidade flutuante. Jornal de resenhas, Folha de São Paulo, 12/8/2000, s/p.

PINTO, Júlio Pimentel. Acidade ilhada de Milton Hatoum. <http:// paisagensdacritica. wordpress.com/2009/03/06/a-cidade-ilhada-de-miltonhatoum>, acesso em 29/8/09.

SEDLMAYER, Sabrina. Perambulações: presença árabe na literatura brasileira. Tiraz: Revista de estudos árabes e das culturas do Oriente Médio. FFLCH/ USP, 2005, p. 10-17.

\section{Textos de apoio teórico}


COMPAGNON, Antoine. O leitor. In: O Demônio da Teoria. Belo Horizonte: UFMG, 2003, p. 139 a 164.

CONNOR, Steven. Teoria e valor cultural. São Paulo: Edições Loyola, 1994.

\section{Entrevistas}

CRISTO, Maria da Luz Pinheiro de. Entrevista com Milton Hatoum. In: CRISTO, Maria da Luz Pinheiro de (Org.). Arquitetura da Memória: ensaios sobre os romances Dois Irmãos, Relato de um certo Oriente e Cinzas do Norte de Milton Hatoum. Manaus: Editora da Universidade Federal do Amazonas / Uninorte, 2007, p. 23-32.

GURGEL, Luiz Henrique. "Não há literatura sem memória". Revista Na ponta do Lápis. Ano IV, No. 8. AGWM Editora e Produções editoriais, junho/2008, p. $2-4$.

LOPES, Jonas. Miltom Hatoum dá entrevista sobe o relançamento de seu primeiro livro. Revisto Bravo (online), 6/8/08. Disponível em <http://bravoline. abril.com.br> Acesso em 3/1/09.

MONTANO, Sônia. Entrevista com Marleide Paula M. Ferreira de Toledo: Hatoum e a arquitetura do romance. Revista Fronteiras, 31/10/2007. Disponível em: <http//<www.fronteirasdopensamento.com.br> Acesso em: 3/1/2009. 